\title{
PERHITUNGAN EFEKTIFITAS LINTASAN PRODUKSI MENGGUNAKAN METODE LINE BALANCING
}

\author{
THE CALCULATION OF EFFECTIVENESS PRODUCTION LINE \\ USING THE LINE BALANCING METHOD
}

Indrani Dharmayanti ${ }^{1)}$, dan Hafif Marliansyah ${ }^{2)}$

${ }^{1,2)}$ Politeknik APP Jakarta, J1. Timbul 34 Jakarta Selatan, 12630, Indonesia ${ }^{*}$ Penulis korespondensi : iindh522@gmail.com

DOI Number : 10.30988/jmil.v3i1.63

Abstract

This study aims to determine how effective and efficient the production line and calculate the optimal time to process a candy product. The data was measured by stopwatch, then tested for uniformity and adequacy to obtain a value to do line balancing analysis using the Killbridge and Wester methods and Rank Position Weight, then performance of the initial line is compared with the results of analysis. The results of analysis using both line balancing methods, show that line efficiency were $76.1 \%$, increasing by $43.1 \%$ from the efficiency of the initial line by $33 \%$. The result of the balance delay $(B D)$ calculation is $23.92 \%$ decreased by $53 \%$, and the smoothness index 17.79 fell by 74.98 from the initial line which means that the proposed production line are more efficient than the initial line. The optimum time needed for production start from sugar tipping to the packaging are 91,29 minutes.

Keywords: line balancing; line efficiency; Killberg \& Wester; Rank Position Weight

\section{Abstrak}

Penelitian bertujuan untuk mengetahui seberapa efektif dan efisien lintasan produksi yang digunakan pada proses produksi permen, serta menghitung waktu optimal yang dibutuhkan dalam produksi. Pengambilan data primer dilakukan dengan metode pengukuran langsung menggunakan jam henti yang selanjutnya diuji keseragaman, dan kecukupan datanya sehingga diperoleh sebuah nilai untuk kemudian dilakukan analisis keseimbangan lini dengan menggunakan metode Killbridge dan Wester dan Rank Position Weight. Selanjutnya performansi lintasan awal dibandingkan dengan hasil analisis keseimbangan lini. Dari hasil analisis menggunakan kedua metode line balancing tersebut diperoleh hasil efisiensi lini sebesar 76,1\%, meningkat sebesar 43,1\% dari efisiensi keadaan lintasan awal sebesar 33\%. Hasil perhitungan balance delay (BD) adalah sebesar 23,92\% turun 53\% dari kondisi awal; dan smoothness index 17,79 turun sebesar 74,98 yang artinya hasil analisis lintasan usulan lebih efisien dibandingkan dengan keadaan lintasan awal. Hasil analisis waktu optimum yang dibutuhkan untuk produksi mulai dari tipping gula sampai proses pengemasan adalah 91,29 menit.

Kata kunci: efisiensi lini produksi, keseimbangan lintasan; Killberg \& Wester; Rank Position Weight 


\section{PENDAHULUAN}

Perkembangan industri saat ini dalam bidang makanan dan minuman mengalami perkembangan pesat. Perkembangan ini membuat industri di bidang makanan dan minuman harus menjalankan sistem produksi dengan efektif dan efisien, melalui penggunaan operator dan jumlah mesin yang minim, tetapi dapat menghasilkan produksi yang tinggi. Hal ini dapat dilihat pada tahun 2015, pertumbuhan industri makanan minuman di Indonesia adalah sebesar $8,16 \%$. Pertumbuhan ini lebih tinggi jika dibanding dengan pertumbuhan industri non migas yaitu 5,21\%. Kemudian tahun 2016 pertumbuhannya meningkat lagi menjadi $8,2-8,5 \%$, tahun 2017 sebesar 9,23\%, dan tahun 2018 pertumbuhannya 9,26\% . Pada tahun 2019 industri makanan dan minuman diprediksikan mengalami pertumbuhan yang relatif stagnan, sebesar $8 \%-9 \%$ [1].

Pesatnya perkembangan industri memaksa perusahaan industri untuk terus berkembang dan berinovasi. Perusahaan yang mampu berkembang dan berinovasi tentu akan senantiasa meningkatkan keunggulannya dalam persaingan di dunia industri. Keunggulan persaingan hanya dapat dicapai apabila perusahaan memiliki manajemen operasi yang efektif. Efektifitas operasi ditentukan oleh jumlah pekerja juga keseimbangan pekerjaan yang ditentukan faktor kinerja manpower dan faktor efisiensi waktu produksi. Pada akhirnya hal ini dapat mengurangi pemborosan waktu dan biaya yang bisa merugikan perusahaan.

Peningkatkan produktivitas dan daya saing salah satunya ditentukan oleh efisiensi produksi, dimana keseimbangan lintasan produksi merupakan faktor penentunya. Untuk mencapai lintasan produksi yang seimbang, waktu tunggu antar stasiun kerja harus minimal agar tidak terjadi penumpukan pekerjaan yang berakibat proses produksi terhambat. Sehingga penyeimbangan lintasan produksi perlu dilakukan agar sistem produksi di perusahaan industri manufaktur lebih baik.PT. ABC merupakan industri yang memproduksi makanan dan minuman. Pada penelitian ini dianalisis lintasan produksi untuk produk permen $X$. Tingkat permintaan akan produk yang tinggi menuntut perusahaan meningkatkan produktivitas agar bisa memenuhi permintaan dengan tepat waktu. Oleh karena itu perusahaan perlu mengimplementasikan manajemen operasionalnya yang efektif efisien.

Tingginya permintaan terhadap produk permen $X$ membuat perusahaan harus mengoptimalkan kinerja karyawan dan mesinnya agar target dapat tercapai. Berbagai upaya telah dilakukan oleh perusahaan untuk mengoptimalkan kinerja mesin dan meningkatkan produktifitas, tetapi tidak memperhatikan efisiensi lintasan pada proses pembuatan produk permen $\mathrm{X}$. Sementara tanpa disadari adanya kendala pada salah satu proses dalam pembuatan permen $\mathrm{X}$ dapat memperlambat waktu proses secara keseluruhan. Alasan inilah yang melatarbelakangi untuk dilakukannya analisis efektifitas lintasan produksi pada proses pembuatan permen $X$ di PT. ABC serta memberikan usulan lintasan produksi yang lebih optimal dengan menggunakan metode line balancing.

\section{METODE PENELITIAN}

Penelitian ini dilakukan di PT. ABC yang berlokasi Jl. Raya Serang, Bitung, Cikupa, Dukuh, Tangerang, Banten, 15710.

Pelaksanaan penelitian ini mengikuti kerangka pemikiran seperti terlihat pada Gambar 1. Data yang terkumpul yaitu waktu proses, stasiun kerja, target produksi, waktu kerja efektif, proses produksi permen $\mathrm{X}$ selanjutnya diuji tingkat kecukupan data, uji keseragaman data, perhitungan efisiensi keadaan lintasan awal, menentukan jumlah stasiun kerja minimum, menerapkan perhitungan menggunakan Metode Killberg 
\& Wester dan Metode Ranked Positional Weight, yang selanjutnya melakukan analisis performansi lini produksi dengan line balancing.

Tahapan penelitian digambarkan pada kerangka penelitian berikut :

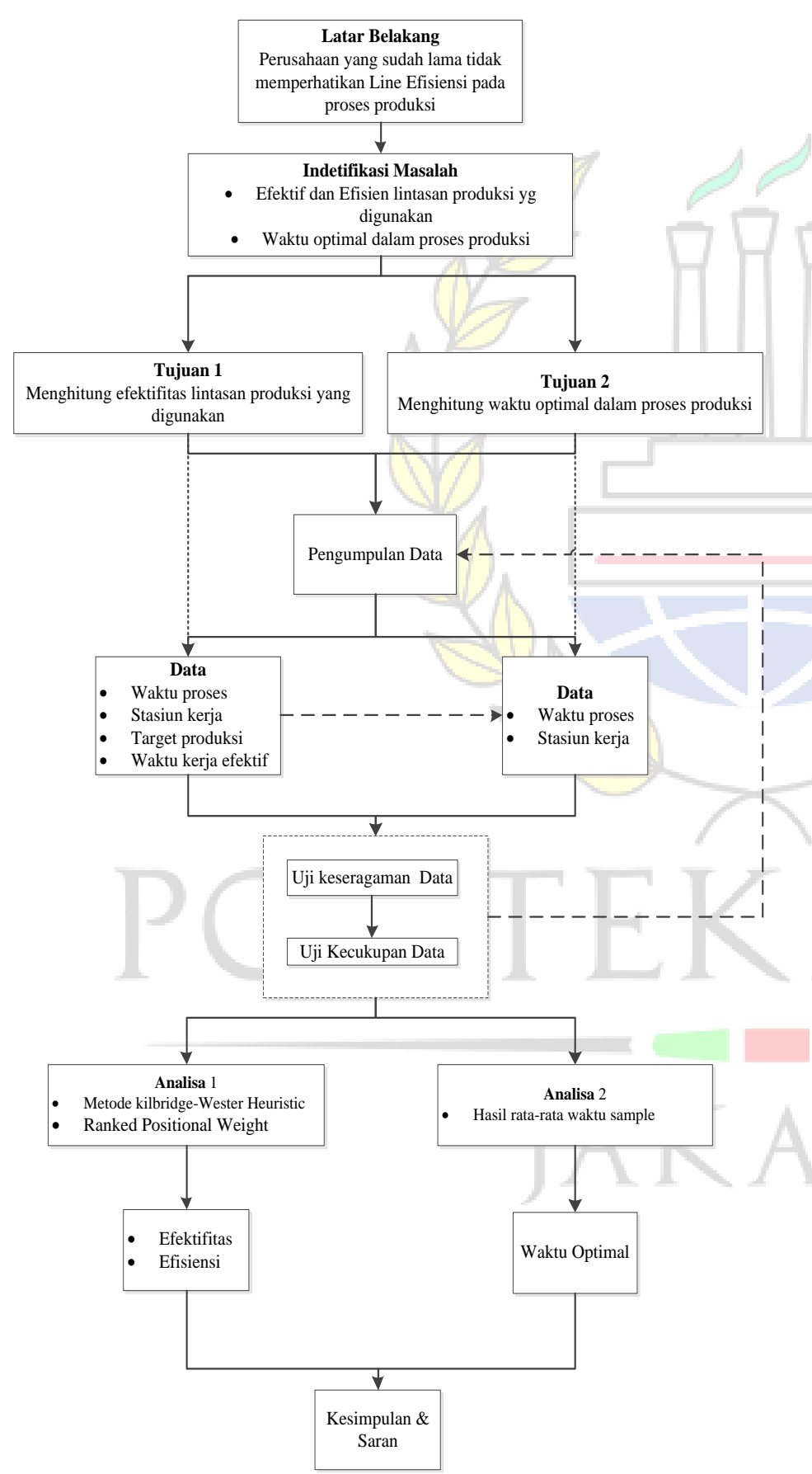

Gambar 1. Kerangka Pemikiran
Menurut Gasperz [2], line balancing yaitu penyeimbangan penugasan elemen tugas dari suatu assembly line ke stasiun kerja untuk meminimalkan stasiun kerja dan idle time di semua stasiun pada output tertentu. Waktu proses per unit produk di tiap tugas dan hubungan sekuen perlu diketahui.

Dalam menghitung efisiensi lintasan produksi, dilakukan penghitungan idle time/ waktu menganggur yaitu selisih station time (ST) dan cycle time (CT), menghitung waktu senggang/balance delay, efisiensi stasiun kerja, efisiensi lintasan produksi/line efficiency), juga smoothet indeks [3].

Terdapat 10 tahap penyelesaian masalah line balancing [2], yaitu :

1. Identifikasi tugas/aktivitas individual yang dilakukan.

2. Tentukan waktu pengerjaan tiap tugas.

3. Tetapkan precedence constraints (apabila terdapat keterkaitan tugas).

4. Tentukan output dari assembly line yang dibutuhkan.

5. Tentukan waktu total untuk produksi output.

6. Hitung waktu siklus/cycle time.

7. Berikan penugasan pada pekerja/mesin.

8. Tetapkan jumlah stasiun kerja (work stations) minimum.

9. Lakukan penilaian efektivitas dan efisiensi solusi.

10. Lakukan perbaikan proses terus-menerus (continuous process improvement). ${ }^{[2]}$

Metode-metode yang digunakan dalam penyelesaian masalah line balancing diantaranya: 1) Metode heuristik seperti metode Ranked Positional Weight (Hegelson and Birine) dan metode Region Approach (Kilbridge`s and Waste); 2) Metode analitik atau matematis dan 3) Metode simulasi. Pada penelitian ini digunakan metode Killberg \& Wester dan Ranked Positional Weight [4] dengan pertimbangan ketersedia data, serta simple, lebih cepat dan mudah diterapkan untuk mendapatkan solusi terbaik dari solusi 
sebelumnya dibanding metode analitik, matematik dan simulasi. Meskipun metode ini tidak optimal, tetapi setidaknya mendekati optiomal.

Metode Ranked Positional Weight diusulkan oleh Helgeson dan Birnie. Malave [5] menyebutkan bahwa pada metode ini penentuan jumlah stasiun kerja dan pembagian tugas dilakukan dengan pembobotan posisi pada tiap tugas hingga tugas-tugas ditempatkan pada semua stasiun.

Tahapan metode ini adalah [4]:

1. Hitung bobot posisi setiap tugas yaitu bobot suatu tugas ditambah bobot tugastugas berikutnya.

2. Urutkan tugas sesuai bobot posisi, yaitu dari yang terbesar sampai terkecil.

3. Tempatkan tugas berbobot terbesar ke suatu stasiun tanpa melanggar precedence constraint dan waktu stasiun tidak melebihi waktu siklus.

4. Lakukan penempatan sampai semua tugas ditempatkan pada stasiun kerja.

Metode Kilbridge Wester dirancang oleh M.Kilbridge dan L.Wester. Pada metode ini, dilakukan pengelompokan tugas-tugas ke dalam sejumlah kelompok yang mempunyai tingkat keterhubungan yang sama.

Langkah-langkah yang digunakan metode Kilbridge Wester adalah sebagai berikut ini [4]:

1. Kelompokan beberapa tugas dalam satu kelompok. Misal kelompok ke-n adalah tugas-tugas yang tidak ada tugas sebelumnya, kelompok ke-n+1 terdiri tugas-tugas yang punya tugas sebelumnya di kelompok ke-n, kelompok ke- $n+2$ terdiri dari tugas-tugas yang punya tugas sebelumnya di kelompok ke$n+1$, seterusnya sampai semua tugas dikelompokkan.

2. Tempatkan tugas di suatu kelompok. Mulai kelompok 1, ke dalam stasiun kerja yang sama. Hasil gabungan terbaik adalah waktu total semua tugas mendekati atau sama dengan waktu siklus. Jika penempatan tugas pada suatu stasiun menyebabkan waktu total semua tugas melebihi waktu siklus, maka

tempatkan tugas tersebut di stasiun kerja berikutnya. Hapus tugas-tugas yang telah ditempatkan dari kelompoknya.

3. Jika terdapat tugas-tugas yang belum ditempatkan di suatu stasiun kerja dan waktu totalnya berjumlah kurang dari waktu siklus, lanjutkan penggabungan dengan tugas setelahnya (kelompok 2).

4. Lakukan kembali langkah 2 dan 3 hingga semua tugas telah tergabung dalam suatu stasiun kerja.

Langkah selanjutnya adalah pengukuran utilisasi yang merupakan pengukuran hasil suatu lini perakitan. Pengukuran dilakukan dengan menghitung efisiensi lini produksi, balance delay, dan smoothness index.

Beberapa penelitian sebelumnya yang menggunakan metode line balancing pada berbagai bidang [6], seperti pada produksi gearbox [7] ; air minum dalam kemasan [8]; produksi keramik [9]; proses produksi sepatu [10]; proses perakitan body bus pada karoseri [11]; produksi furniture [12] juga pada proses produksi alat musik [13] . Penelitian-penelitian tersebut menggunakan berbagai metode yang berbeda, sehingga bisa menjadi referensi bagi penelitian ini.

\section{HASIL DAN PEMBAHASAN}

\subsection{Proses Produksi}

Penelitian ini mengambil studi kasus proses produksi permen X di PT ABC Factory Cikupa. Saat melakukan penelitian tentang lini produksi, tentu hal yang harus dilakukan adalah memetakan peta operasi (Operation Planning Chart/OPC), yaitu diagram yang menggambarkan tahap demi tahap produksi dari raw material hingga menjadi komponen atau produk jadi sesuai urutan operasi. Pada produksi permen $\mathrm{X}$, terdapat enam belas aktivitas proses, yaitu proses tipping gula, dua kali pengadukan, tiga kali proses penurunan kadar air, penyimpanan gula, 
pemindahan, pencetakan permen, inspeksi, naked production, pembungkusan, pengisian kemasan dan pengemasan akhir. Peta proses operasi dapat dilihat pada Gambar 2.

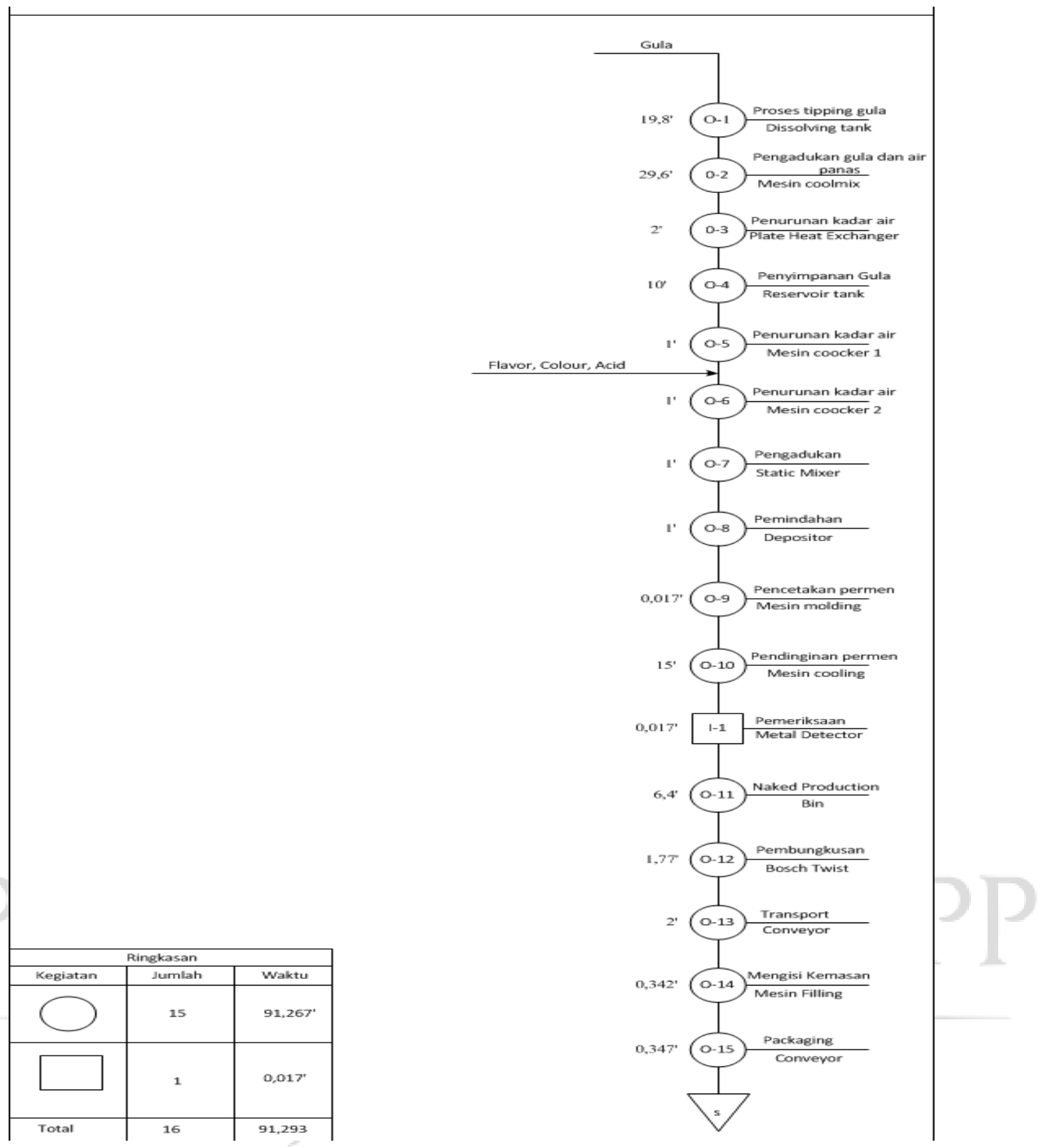

Gambar 2. Peta operasi produk X

Peta proses operasi produk $\mathrm{X}$ memuat informasi mengenai waktu siklus yang dibutuhkan, material yang digunakan, dan tempat atau alat atau mesin yang dipakai. Sebelum melakukan perhitungan, maka dilakukan dulu uji kecukupan dan keseragaman data. Uji kecukupan data dapat dilakukan untuk melakukan proses operasi produk X.

\subsection{Uji kecukupan data}

Pengujian dilakukan untuk melihat keterwakilan populasi dari data yang diambil. Bila hasil perhitungan yang diperoleh (N') kurang dari jumlah pengamatan $(\mathrm{N})$ yang dilakukan, maka data telah mencukupi. Pengujian kecukupan data ini menggunakan tingkat ketelitian sebesar

Page $\mid 47$ 
(S) 5\% dan tingkat keyakinan sebesar (K) 95\% . Berikut ini adalah contoh perhitungan kecukupan data.

Berikut ini adalah contoh perhitungan kecukupan data pada stasiun tipping.

$$
\begin{aligned}
& N^{\prime}=\left[\frac{k / s \sqrt{N \sum x^{2}-\left(\sum x\right)^{2}}}{\sum x}\right]^{2} \\
& \mathrm{~N}^{\prime}=\left[\frac{40 \sqrt{10(3922)-(39204)}}{198}\right] \\
& \mathrm{N}=0,653 \\
& \text { Dimana: } \\
& \mathrm{k} \quad=\text { Tingkat Keyakinan } \\
& \mathrm{S} \quad=\text { Derajat Ketelitian } \\
& \mathrm{N}=\text { Jumlah Data Pengamatan } \\
& \mathrm{N}, \quad=\text { Jumlah Data Teoritis } \\
& \mathrm{X}=\text { Data Pengamatan }
\end{aligned}
$$

$$
\begin{aligned}
& \text { Dimana }: \\
& \text { BKA }=\text { Batas Kontrol Atas } \\
& \mathrm{BKB}=\text { Batas Kontrol Bawah } \\
& \overline{\mathrm{X}}=\text { Nilai Data Rata-Rata } \\
& \sigma \quad=\text { Standar Deviasi } \\
& \mathrm{k} \quad=\text { Tingkat Keyakinan }
\end{aligned}
$$

Hasil uji keseragaman data pada stasiun tipping dapat dilihat pada Gambar 3.

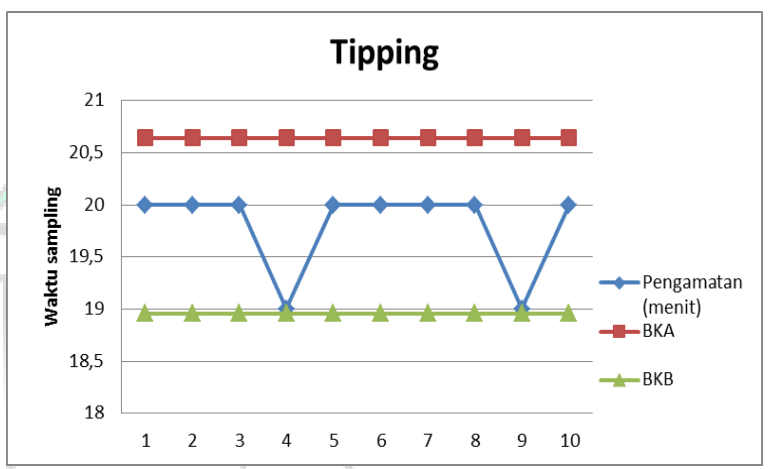

Gambar 3. Peta Kontrol Uji Keseragaman Data

Karena $0,653<10$, maka pengamatan yang dilakukan di stasiun tipping dianggap cukup. Dari hasil perhitungan kecukupan data di semua stasiun terlihat bahwa data telah cukup memenuhi.

\subsection{Uji keseragaman data}

Pengujian dilakukan untuk melihat apakah terdapat data (waktu siklus) pengamatan yang berada diluar batas kontrol. Pengujian ini berdasarkan tingkat keyakinan $95 \%$. Pengujian keseragaman data waktu siklus untuk Operasi-1 adalah sebagai berikut:

$$
\begin{aligned}
& \sigma=\sqrt{\frac{\sum(x-\bar{x})^{2}}{N-1}} \\
& \sigma=\sqrt{\frac{\begin{array}{l}
(20-19,8)^{2}+(20-19,8)^{2}+(20-19,8)^{2} \\
+\cdots \ldots \ldots+(19-19,8)^{2}+(20-19,8)^{2}
\end{array}}{10-1}} \\
& \sigma=0,42 \\
& \mathrm{BKA}=\bar{x}+\mathrm{k} \sigma \\
& =19,8+(2 \times 0,42) \\
& =20,64 \\
& \mathrm{BKB}=\bar{x}-\mathrm{k} \sigma \\
& =19,8-(2 \times 0,42) \\
& =18,96
\end{aligned}
$$

Data grafik diatas terlihat bahwa waktu sampling berada pada daerah antara BKA yang lainnya

\subsection{Efisiensi keadaan lintasan awal}

Setelah data diketahui cukup dan seragam selanjutnya kelompokan stasiun kerja berdasarkan data hasil pengamatan stasiun kerja awal.

Tabel 1. Pembagian Stasiun Kerja Lintasan Awal

\begin{tabular}{ccccc}
\hline $\begin{array}{c}\text { Stasiun } \\
\text { Kerja }\end{array}$ & Elemen & Ti & Jumlah Waktu & Efisiensi \\
\hline I & O-1 & 19.8 & 19.8 & $43 \%$ \\
II & O-2 & 29.6 & 45.62 & $100 \%$ \\
& O-3 & 2 & & \\
& O-4 & 10 & & \\
& O-5 & 1 & & \\
& O-6 & 1 & & \\
& O-7 & 1 & & \\
& O-8 & 1 & & \\
& O-9 & 0.017 & & \\
& & & & \\
III & O-10 & 15 & $15 \%$ & \\
& I-1 & 0.017 & & \\
IV & O-11 & 6.4 & 6.4 & \\
V & O-12 & 1.77 & 3.77 & \\
& O-13 & 2 & & \\
VI & O-14 & 0.342 & 0.69 & \\
& O-15 & 0.347 & & \\
\hline
\end{tabular}

Page $\mid 48$ dan BKB. Demikian juga untuk stasiun kerja 


\section{Line Efficiency (LE)}

Line efficiency atau efisiensi lintasan menunjukan ukuran tingkat efisiensi suatu lintasan yang dinyatakan dalam presentase. $\Sigma$ ST adalah total waktu untuk menyelesaikan proses adalah 91,29 menit. Pada lintasan awal terdapat 6 stasiun kerja, dan waktu maksimal stasiun kerja adalah 45,617. Perhitungan efisiensi lini adalah sebagai berikut:

$$
\begin{aligned}
\mathrm{LE} & =\frac{\sum S T}{(k)(\text { Wmaks })} \times 100 \% \\
\mathrm{LE} & =\frac{91,293}{(6)(45,617)} \times 100 \% \\
\mathrm{LE} & =33 \%
\end{aligned}
$$

Dimana :

STi = Waktu stasiun kerja ke-i.

$\mathrm{k}=$ Jumlah stasiun kerja.

Wmaks = waktu stasiun kerja paling maksimal

\section{Balance Delay $(D)$}

Balance Delay merupakan ukuran dari ketidakefisienan lintasan yang dihasilkan dari waktu menganggur sebenarnya yang disebabkan karena pengalokasian yang kurang sempurna di antara stasiun stasiun kerja. Perhitungannya sebagai berikut :

$$
\begin{aligned}
& D=100 \%-\text { Line Efficiency } \\
& D=100 \%-33 \% \\
& D=77 \%
\end{aligned}
$$

\section{Smoothest Index (SI)}

Smoothest index merupakan indeks yang menunjukkan kelancaran relatif atau cara untuk mengukur tingkat waktu tunggu relatif dari penyeimbangan lini perakitan tertentu. Untuk lintasan awal data mengacu pada Tabel 1. Perhitungannya sebagai berikut:

$$
\begin{aligned}
& S I=\sqrt{\sum(S T \max -S T i)^{2}} \\
& S I=\sqrt{\sum_{\begin{array}{c}
(45,617-19,8)^{2}+(45,617-45,617)^{2} \\
+\cdots \cdots \ldots+(45,617-0,342)^{2} \\
+(45,617-0,347)^{2}
\end{array}}^{\text {SI }=92,78}}
\end{aligned}
$$

Dimana :

$S T_{\max }=$ waktu maks di stasiun kerja

STi = waktu stasiun di stasiun kerja ke-i.

\subsection{Perhitungan cycle time}

Waktu siklus (cycle time) yaitu batas waktu kerja maksimum dari setiap workstation. Waktu maksimum pada Tabel 1 adalah 29,6 menit.

Karena $\mathrm{C} \geq \mathrm{t}_{\text {max }}$,

$\mathrm{C}=$ waktu siklus

$\mathrm{t}_{\max }=$ waktu terbesar dari keseluruhan elemen kerja

$\mathrm{t}_{\max }=29,6$ menit $\approx 30$ menit,

sehingga waktu siklus adalah 30 menit.

\subsection{Menentukan jumlah stasiun kerja minimum}

Setelah menentukan interval waktu siklus, maka jumlah stasiun kerja yang efisien dapat ditetapkan. Berdasar data dari Tabel 1 dilakukan perhitungan jumlah stasiun kerja minimal sesuai persamaan 6 berikut:

$$
\begin{aligned}
& W=\min \text { integer } \frac{T w c}{T w s} \\
& W=\min \text { integer } \frac{91,293}{30}=3,043 \\
& W=4 \text { Stasiun Kerja } \\
& \text { Dimana : } \\
& \text { Twc }=\text { total waktu proses } \\
& \text { Tws }=\text { waktu siklus }
\end{aligned}
$$

Berdasar perhitungan di atas, diketahui bahwa jumlah stasiun kerja dapat dikurangi dari 6 stasiun menjadi 4 stasiun.

\subsection{Menerapkan perhitungan dengan menggunakan metode Killberg \& Wester}

Pada prinsipnya metode ini berusaha membebankan tugas terlebih dahulu pada operasi yang memiliki tanggung jawab pendahuluan (precedence) yang besar, sehingga sebelum melakukan perhitungan, langkah pertama yang perlu dilakukan adalah menetapkan precedence constraints, sebagaimana terlihat pada Gambar 4. 


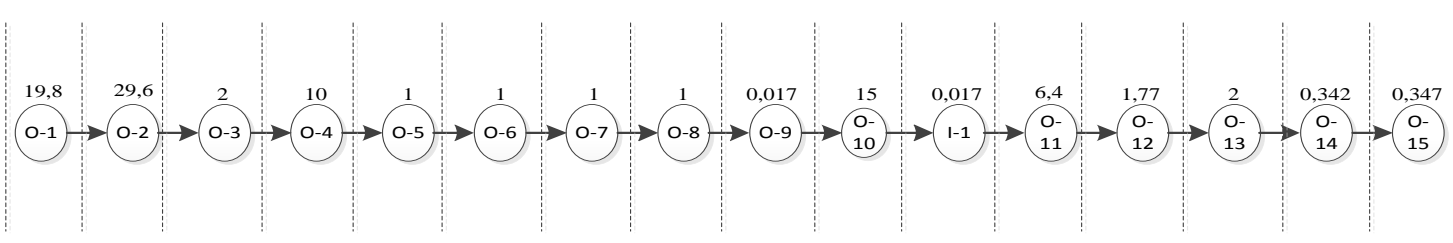

Gambar 4. Pembagian Region Pada Precedence Diagram Killbridge \& Wester

Tabel 2. Pengelompokan Region Elemen Kerja

\begin{tabular}{clccc|c}
\hline $\begin{array}{c}\text { Stasiun } \\
\text { Kerja }\end{array}$ & \multicolumn{1}{c}{ Elemen } & Ti & $\begin{array}{c}\text { Jumlah } \\
\text { Waktu }\end{array}$ & $\begin{array}{c}\text { Predece- } \\
\text { ssor }\end{array}$ & \multirow{2}{*}{ Ki } \\
\cline { 1 - 4 } I & Tipping & 19.8 & 19.8 & O-1 & 1. \\
II & Coolmix & 29.6 & 29.6 & O-2 & \\
III & Plate Heat Exchanger & 2 & 2 & O-3 & \\
IV & Reservor tank & 10 & 10 & O-4 & \\
V & Cooker 1 & 1 & 1 & O-5 \\
VI & Cooker 2 & 1 & 1 & O-6 \\
VII & Static mixer & 1 & 1 & O-7 \\
VIII & Depositor & 0.017 & 0 & O-9 \\
IX & Molding & 15 & 15 & O-10 \\
X & Cooling & 0.017 & 0.017 & I-1 \\
XI & Metal detector & 6.4 & 6.4 & O-11 \\
XII & Naked production & 1.77 & 1.8 & O-12 \\
XIII & Wrapping & 2 & 2 & O-13 \\
XIV & Transport to filling & 0.342 & 0.3 & O-14 \\
XV & Filling & 0.347 & 0.3 & O-15 \\
XVI & Packaging & 0.3 & \\
\hline
\end{tabular}

Setelah didapat jumlah stasiun kerja teoritis, maka dapat dilakukan pengelompokkan stasiun kerja berdasarkan tugas-tugasnya. Total dalam satu stasiun harus lebih kecil dari waktu siklusnya (30 menit), sedangkan efisiensi diambil dari (jumlah waktu pada setiap stasiun kerja/waktu maksimal) dan dinyatakan dalam presentase.

Tabel 3. Pembagian stasiun kerja Killbridge dan Wester
Berdasarkan Tabel 3 maka dapat dilakukan perhitungan performansi untuk metode Killbrige \& Wester berikut :

\section{Line Efficiency}

Line efficiency atau efisiensi lintasan menunjukan ukuran tingkat efisiensi suatu lintasan yang dinyatakan dalam presentase, untuk perhitungannya sebagai berikut:

$$
\begin{aligned}
& \mathrm{LE}=\frac{\sum S T}{(k)(\text { Wmaks })} \times 100 \% \\
& \mathrm{LE}=\frac{91,293}{(4)(30)} \times 100 \% \\
& \mathrm{LE}=76,077 \%
\end{aligned}
$$

\section{Balance Delay}

Balance delay merupakan ukuran dari ketidakefisienan lintasan yang dihasilkan dari waktu menganggur sebenarnya yang disebabkan karena pengalokasian yang kurang sempurna di antara stasiun-stasiun kerja. untuk perhitungannya sebagai berikut:

$$
\begin{aligned}
& D=100 \%-\text { Line Efficiency } \\
& D=100 \%-76,077 \% \\
& D=23,923 \%
\end{aligned}
$$

\section{Smoothest Index}

Smoothest index merupakan indeks yang menunjukkan kelancaran relatif atau cara untuk mengukur tingkat waktu tunggu relatif dari penyeimbangan lini perakitan tertentu. Untuk perhitungannya sebagai berikut:

$$
\begin{gathered}
S I=\sqrt{\sum(\text { STmax }-S T i)^{2}} \\
S I=\sqrt{\sum_{\begin{array}{c}
(30-19,8)^{2}+(30-29,6)^{2}+ \\
(30-2)^{2}+\cdots \ldots+ \\
(30-0,342)^{2}+(30-0,347)^{2}
\end{array}}} \\
\text { SI }=17,797
\end{gathered}
$$




\subsection{Perhitungan dengan menggunakan metode Ranked Positional Weight}

Berdasarkan precedence diagram awal pada Gambar 4, maka tiap-tiap elemen kerja dapat dihitung bobot posisinya. Dimana bobot posisi elemen kerja adalah waktu baku elemen kerja tersebut ditambah waktu baku elemen-elemen kerja yang mengikutinya. Setelah mencari bobot posisi, kemudian elemen kerja diurutkan dari bobot posisi yang paling besar sampai yang paling kecil, sebagaimana terlihat pada Tabel 4.

Tabel 4. Pengurutan Operasi Berdasarkan Metode Ranked Positional Weights

\begin{tabular}{|c|c|c|c|}
\hline RPW-i & Bobot & Waktu Proses & Rangking \\
\hline & & (menit) & \\
\hline RPW-1 & 91.293 & 19.8 & 1 \\
\hline RPW-2 & 71.493 & 29.6 & 2 \\
\hline RPW-3 & 41.893 & 2 & 3 \\
\hline RPW-4 & 39.893 & 10 & 4 \\
\hline RPW-5 & 29.893 & 1 & 5 \\
\hline RPW-6 & 28.893 & 1 & 6 \\
\hline RPW-7 & 27.893 & 1 & 7 \\
\hline RPW-8 & 26.893 & 1 & 8 \\
\hline RPW-9 & 25.893 & 0.017 & 9 \\
\hline RPW-i & Bobot & Waktu Proses & Rangking \\
\hline 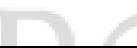 & 17 & (menit) & \\
\hline RPW-10 & 25.876 & 15 & 10 \\
\hline RPW-11 & 10.876 & 0.017 & 11 \\
\hline RPW-12 & 10.859 & 6.4 & 12 \\
\hline RPW-13 & 4.459 & 1.77 & 13 \\
\hline RPW-14 & 3 & 2 & 14 \\
\hline RPW-15 & 0.689 & 0.342 & 15 \\
\hline RPW-16 & 0.347 & 0.347 & 16 \\
\hline
\end{tabular}

Langkah selanjutnya adalah berdasarkan urutan bobot RPW (Ranked Positional Weights), maka elemen-elemen kerja disusun ke dalam stasiun kerja. Jumlah stasiun minimal berdasar perhitungan sebelumnya adalah 4 stasiun kerja.

Penyusunan stasiun kerja memperhatikan waktu proses (Ti), jumlah waktu-waktu proses pada tiap stasiun kerja (ST) dan waktu siklus (CT). Pembagian stasiun kerja dengan menggunakan metode RPW dapat dilihat pada Tabel 5.

Tabel 5. Pembagian Stasiun Kerja Ranked Positional Weight

\begin{tabular}{ccccc}
\hline $\begin{array}{c}\text { Stasaiun } \\
\text { Kerja }\end{array}$ & Elemen & Ti & $\begin{array}{c}\text { Jumlah } \\
\text { Waktu }\end{array}$ & CT - ST \\
\hline I & O-1 & 19.8 & 19.8 & 10.20 \\
II & O-2 & 29.6 & 29.6 & 0.40 \\
III & O-3 & 2 & 16.08 & 13.98 \\
& O-4 & 10 & & \\
& O-5 & 1 & & \\
& O-6 & 1 & & \\
& O-7 & 1 & & \\
& O-8 & 1 & & \\
IV & O-9 & 0.017 & & \\
& O-10 & 15 & 25.88 & 4.12 \\
& I-1 & 0.017 & & \\
& O-11 & 6.4 & & \\
& O-12 & 1.77 & & \\
& O-13 & 2 & & \\
& O-14 & 0.342 & & \\
& O-15 & 0.347 & & \\
\hline
\end{tabular}

Berdasarkan tabel diatas maka didapatkan pehitungan performansi lintasan produksi untuk metode Ranked Positional Weights, sebagai penjelasan berikut dibawah ini :

\section{Line Efficiency}

Line efficiency atau efisiensi lintasan menunjukan ukuran tingkat efisiensi suatu lintasan yang perhitungannya sebagai berikut:

$$
\begin{aligned}
\mathrm{LE} & =\frac{\sum S T}{(k)(\text { Wmaks) }} \times 100 \% \\
\mathrm{LE} & =\frac{91,293}{(4)(30)} \times 100 \%
\end{aligned}
$$

$$
\mathrm{LE}=76,077 \%
$$

\section{Balance Delay}

Balance delay/ketidakefisienan lintasan dari waktu menganggur yang disebabkan pengalokasian yang kurang sempurna antara stasiun-stasiun kerja. Dari hasil perhitungan pada persamaan 10, dapat dihitungan ketidakefisienan lintasan sebagai berikut: 


$$
\begin{aligned}
& \mathrm{D}=100 \%-\text { Line Efficiency } \\
& \mathrm{D}=100 \%-76.077 \% \\
& \mathrm{D}=23,923 \%
\end{aligned}
$$

\section{Smoothest Index}

Smoothest index/indeks yang menunjukkan kelancaran relatif atau cara untuk mengukur tingkat waktu tunggu relatif dari penyeimbangan lini perakitan tertentu. Untuk perhitungannya sebagai berikut:

$$
\begin{gathered}
S I=\sqrt{\sum(\text { STmax }- \text { STi })^{2}} \\
S I=\sqrt{\begin{array}{r}
(30-19,8)^{2}+(30-29,6)^{2}+ \\
(30-2)^{2}+\cdots \ldots+(30-0,342)^{2} \\
+(30-0,347)^{2}
\end{array}} \\
\text { SI }=17,79
\end{gathered}
$$

\subsection{Analisis performansi lini produksi saat ini dengan hasil performansi line balancing}

Berikut adalah perbandingan performansi keseimbangan lini produksi pada lintasan awal dengan hasil perhitungan dengan metode Killbridge \& Wester dan Ranked Positional Weights:

Tabel 6. Hasil Perhitungan Keseimbangan Lini Produksi

\begin{tabular}{lccc}
\hline $\begin{array}{c}\text { Keseimbangan } \\
\text { Lini }\end{array}$ & $\begin{array}{c}\text { Line } \\
\text { Efficiency }\end{array}$ & $\begin{array}{c}\text { Balance } \\
\text { Delay }\end{array}$ & $\begin{array}{c}\text { Smoothing } \\
\text { Index }\end{array}$ \\
\hline Lintasan awal & $33 \%$ & $67 \%$ & 92.78 \\
$\begin{array}{l}\text { Killbridge \& } \\
\text { Wester }\end{array}$ & $76.08 \%$ & $23.92 \%$ & 17.79 \\
$\begin{array}{l}\text { Ranked } \\
\text { Positioned }\end{array}$ & $76.08 \%$ & $23.92 \%$ & 17.79 \\
Weight & & & \\
\hline
\end{tabular}

Metode keseimbangan lini yang dapat di pertimbangkan adalah metode Killbridge \& Wester dan Metode Ranked Positioned Weight. Pada kondisi saat ini, efesiensi lini yang didapatkan hanya sebesar 33\%, namun setelah dilakukan perbaikan maka efesensi lini meningkat menjadi 76,08\% . Peningkatan efesiensi lini ini disebabkan karena proses pengerjaan tiap-tiap operasi yang efektif pada masing-masing stasiun kerja. Dengan meningkatnya efesiensi lini, menyebabkan penurunan Balance Delay (BD) dari $67 \%$ menjadi $23,92 \%$.

Keseimbangan beban kerja yang terjadi menyebabkan Smootness Index (SI) yang semakin baik, yaitu dari 92,78 menjadi 17,79. Dengan melihat performasi di atas, maka dengan metode line balancing, maka proses produksi dapat lebih efisien, dan harapannya dapat meningkatkan produktivitas perusahaan.

\section{KESIMPULAN}

Setelah melakukan pengolahan data dan analisa, maka dapat ditarik kesimpulan sebagai berikut :

1. Dari hasil perhitungan diketahui bahwa efesiensi yang terjadi pada keadaan lintasan awal lantai produksi permen $\mathrm{x}$ cukup rendah. Hal ini ditunjukkan melalui perhitungan Line Efficiency (LE) sebelum dilakukan keseimbangan lini adalah 33\% . Sedangkan untuk Balance Delay (BD) sebesar 77\% dan Smoothing Index sebesar 92,78. Metode keseimbangan lini yang digunakan dalam perhitungan efisiensi lintasan adalah metode Killbridge \& Wester dan metode Ranked Positioned Weight, dimana dengan menggunakan ke dua metode ini didapatkan nilai Line Effeciency (LE) sebesar 76,08\%, dengan Balance Delay (BD) $23,92 \%$ dan Smoothing Index (SI) 17,79. Sehingga didapatkan jumlah stasiun kerja yang diusulkan sebanyak empat stasiun kerja, berkurang tiga stasiun kerja dari sebelumnya memiliki tujuh stasiun kerja. Hal ini bertujuan untuk menyeimbangkan beban kerja antara setiap stasiun kerja yang ada sehingga meningkatkan efesiensi serta efektifitas pada lintasan produksi.

2. Dari hasil perhitungan dapat diketahui waktu optimum yang dibutuhkan dalam memproduksi permen $\mathrm{x}$ mulai dari tipping gula sampai proses pengemasan 
adalah 91,29 menit. Penelitian ini dapat mengefisienkan lintasan produksi dan mengurangi waktu tunggu dari stasiun kerja ke stasiun kerja selanjutnya.

\section{DAFTAR PUSTAKA}

[1] Kementerian Perindustrian, Analisis Perkembangan Industri, Pusdatin Kemenperin, 2019.

[2] V. Gaspersz, Production Planning \& Inventory Control, Jakarta: Gramedia Pustaka Utama, 2004.

[3] T. Baroto, Perencanaan dan Pengendalian Produksi, Jakarta: Ghalia Indonesia, 2002.

[4] A.H. Halim, Perencanaan dan Pengendalian Produksi : Keseimbangan Lintasan, Bandung: Institut Teknologi Bandung, 2003.

[5] C. Malave, Approach to Line Balancing Comsoal \& RPW, Texas A\&M University, 2000.

[6] Pachghare, Vrittika, R. S. Dalu, "Assembly Line Balancing Methods - A Case Study", International Journal of Science and Research (IJSR), volume 3, issue 5, May, hal. 1901-1905, 2014.

[7] Hamza, R.M. Ali and J.Y.-AlManaa, "Selection of Balancing Method for Manual Assembly Line of Two Stages Gearbox", Global Perspectives on Engineering Management, vol. 2, issue 2, May, hal. 70-81, 2013.

[8] Daelima,V. Fiesta, E. Febianti, dan M.A. Ilhami, "Analisis Keseimbangan Lintasan untuk Meningkatkan Kapasitas Produksi dengan Pendekatan Line Balancing dan Simulasi”, Jurnal Teknik
Industri, vol.1, no.2, Juni, hal 107113, 2013.

[9] Sinaga dan T. Sarma, "Pengukuran Keseimbangan Lintasan Produksi Keramik Dengan Metode Helgeson Dan Birnie di PT.XYZ", Jurnal Teknologi Technoscientia, vol. 7, no. 1, Agustus, 2014.

[10] I. Purnamasari dan A.S. Cahyana, "Line Balancing Dengan Metode Ranked Position Weight (RPW)", Spektrum Industri, vol. 13, no. 2, hal. 115 - 228, 2015.

[11] M. Djunaidi dan Angga, "Analisis Keseimbangan Lintasan (Line Balancing) Pada Proses Perakitan Body Bus Pada Karoseri Guna Meningkatkan Efisiensi Lintasan", Jurnal Ilmiah Teknik Industri, vol. 5, no. 2, hal. $77-84,2017$.

[12] Ekoanindiyo, F. Ardiansyah dan L. Helmy, "Meningkatkan Efisiensi Lintasan Kerja Menggunakan Metode RPW dan KillbridgeWestern", Dinamika Teknik, vol. X, no. 1, Januari, hal 16-26, 2017.

[13] Pratama dan F. Yoga, "Analisis Keseimbangan Lintasan Produksi Pada Kelompok Kerja Backpost And Rib Menggunakan Metode Ranked Positional Weight (Studi Kasus Pada PT. Yamaha Indonesia)", skripsi, Universitas Islam Indonesia, Yogyakarta, 2018.

\section{Biografi Penulis}

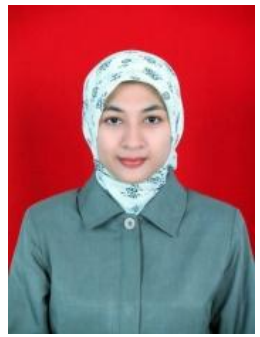

Penulis yaitu Dr. Indrani Dharmayanti, merupakan dosen Politeknik APP Jakarta. Pendidikan S1 ditempuh di IPB (2009) pada program studi Agribisnis. Kemudian melanjutkan master pada Sekolah Pascasarjana IPB dengan program studi 
Pengelolaan Sumberdaya Pesisir dan Lautan (2006) dan melanjutkan program doktor di Teknologi Industri Pertanian (2015) IPB. Pengalaman sebagai pengajar di Lembaga Pendidikan negeri dan swasta sejak tahun 2009 pada bidang pengadaan barang dan jasa, riset operasi, metode penelitian, ekonomi teknik, sistem manufaktur dan psikologi industri. Pada bidang penelitian yang menjadi minat penulis yaitu bidang sosial ekonomi, procurement, manajemen operasi, dan riset operasi (optimasi dan simulasi). Dalam penelitian ini penulis bekerjasama dengan Hafif Marliansyah.

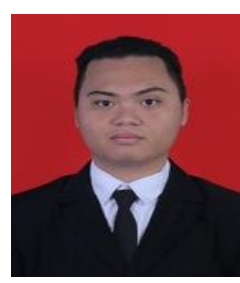

Hafif Marliansayah, Amd. adalah lulusan Politeknik APP.Dilahirkan di Cirebon, 2 Maret 1996. Lulus dari Politeknik APP pada tahun 2017 dari jurusan manajemen produksi. Mempunyai pengalaman bekerja pada perusahaan pergudangan, garmen, sparepart, dan food $\&$ beverage. 